\title{
Changes in mode of travel to work: a natural experimental study of new transport infrastructure
}

\author{
Eva Heinen ${ }^{*}$, Jenna Panter ${ }^{1}$, Roger Mackett ${ }^{2}$ and David Ogilvie ${ }^{1}$
}

\begin{abstract}
Background: New transport infrastructure may promote a shift towards active travel, thereby improving population health. The purpose of this study was to determine the effect of a major transport infrastructure project on commuters' mode of travel, trip frequency and distance travelled to work.

Methods: Quasi-experimental analysis nested within a cohort study of 470 adults working in Cambridge, UK. The intervention consisted of the opening of a guided busway with a path for walking and cycling in 2011. Exposure to the intervention was defined as the negative of the square root of the shortest distance from home to busway. The outcome measures were changes in commute mode share and number of commute trips - both based on a seven-day travel-to-work record collected before (2009) and after (2012) the intervention - and change in objective commute distance. The mode share outcomes were changes in the proportions of trips (i) involving any active travel, (ii) involving any public transport, and (iii) made entirely by car. Separate multinomial regression models were estimated adjusting for commute and sociodemographic characteristics, residential settlement size and life events.
\end{abstract}

Results: Proximity to the busway predicted an increased likelihood of a large (>30 \%) increase in the share of commute trips involving any active travel (relative risk ratio [RRR] 1.80, $95 \% \mathrm{Cl} 1.27,2.55$ ) and a large decrease in the share of trips made entirely by car (RRR $2.09,95 \% \mathrm{Cl} 1.35,3.21$ ), as well as a lower likelihood of a small $(<30 \%)$ reduction in the share of trips involving any active travel (RRR $0.47,95 \% \mathrm{Cl} 0.28,0.81$ ). It was not associated with changes in the share of commute trips involving any public transport, the number of commute trips, or commute distance.

Conclusions: The new infrastructure promoted an increase in the share of commuting trips involving active travel and a decrease in the share made entirely by car. Further analysis will show the extent to which the changes in commute mode share were translated into an increase in time spent in active commuting and consequent health gain.

Keywords: Adults, Active travel, Bus, Commuting, Evaluation, Intervention, Natural experimental study, Transport infrastructure, Travel behaviour, Modal shift

\section{Introduction}

Active travel can provide a sufficient level of physical activity to improve health and well-being [1]. This activity may be particularly beneficial in the form of active commuting, which offers the potential to easily incorporate regular walking and cycling into daily life [2]. However, not all environments are equally supportive for walking

\footnotetext{
* Correspondence: eh480@medschl.cam.ac.uk

${ }^{1}$ MRC Epidemiology Unit and UKCRC Centre for Diet and Activity Research (CEDAR), School of Clinical Medicine, University of Cambridge, Cambridge Biomedical Campus, Box 285, Cambridge CB2 0QQ, UK

Full list of author information is available at the end of the article
}

and cycling. Although cross-sectional studies show that characteristics of the built environment are associated with differences in travel behaviour, including walking and cycling [3-7], few intervention studies exist in this area $[8-10]$ and this limits the possibility of determining the causal effects of environmental changes on travel behaviour [11-13].

The primary outcome of most interest to health researchers studying interventions in this area is often a change in time spent in active travel $[14,15]$. However, understanding the population health impacts of 
infrastructural interventions may require an approach that considers a wider range of outcomes [16]. Change in time spent in active travel may be a result of changes in the distance, speed, and number of trips and in the proportions of these made by each mode of transport (mode share). The patterns and determinants of changes in these characteristics may differ, and they may also have different long-term health consequences. For example, a reduction in car travel could confer population health benefits including reduced exposure to air pollution and injuries, while an increase in walking or cycling could confer individual health benefits resulting from increased physical activity [17].

The natural experimental study [18] 'Commuting and Health in Cambridge' offers an opportunity to study the effect of new transport infrastructure on travel behaviour [19]. It investigates the introduction of a guided busway, which is the longest of its kind in the world and is unique in providing high-quality facilities for three modes of transport: bus, cycling and walking. Building on existing intervention studies, this study explores changes in travel behaviour in more depth by examining multiple outcomes. Specifically, this paper aims to determine the effect of the intervention on changes in mode share, number of trips and distance travelled on the journey from home to work.

\section{Methods}

\section{Intervention: the Cambridgeshire Guided Busway}

The busway is situated in Cambridgeshire, UK. The city of Cambridge has a comparatively affluent and welleducated population. $45 \%$ of its commuting population travel to work by car or taxi, $28 \%$ by bicycle, $15 \%$ on foot and $9 \%$ by public transport [20].

The busway comprises a $25 \mathrm{~km}$ off-road guideway for buses, with a parallel path that can be used for walking and cycling (Fig. 1), in two sections: one between the market town of St Ives and the northern edge of Cambridge, and the other between Cambridge railway station and the southern fringe at Trumpington. The busway links surrounding villages, the urban fringe, the city centre and several major employment sites [21]. Opened in 2011, it offers better than average facilities for bus use, cycling and walking and was intended to change travel behaviour in order to reduce traffic congestion $[22,23]$.

\section{Study sample}

Questionnaire data were collected by post annually between 2009 and 2012 as part of a natural experimental cohort study. Participants, who were recruited mainly through workplaces, were aged 16 or over, working in areas of Cambridge to be served by the busway and living within approximately $30 \mathrm{~km}$ of the city centre [19]. To avoid biasing recruitment and responses, the study was presented to participants as a study of 'commuting and health' and the aim of evaluating the busway was not made explicit.

In this paper we analyse the first (pre-intervention) and fourth (final, post- intervention) survey waves. 1164 participants took part in the first wave, of whom 500 (43\%) also took part in the fourth wave.

The Hertfordshire Research Ethics Committee approved the study and the baseline data collection (reference number: 08/H0311/208) and the Cambridge Psychology Research Ethics Committee granted approval for the follow-up data collection used in this analysis (reference number: 2014.14). All participants provided written informed consent.

\section{Outcomes}

Three outcomes were modelled: change in commute mode share, change in number of commute trips and change in commute distance.

The first two outcomes were derived from a seven-day commute travel diary [24]. For each day, respondents were asked to report the day of the week, their working hours and their mode(s) of travel to and from work, or to positively indicate that they had not travelled to work that day. We excluded respondents who had returned a blank travel diary in either wave $(n=28)$ or had accounted for fewer than three days of the week $(n=2)$, leaving 470 respondents included in analysis. We truncated the travel diary to the first seven reported consecutive days if more days were reported. Individuals reporting fewer or more than seven consecutive days, failing to report an apparently missing trip to or from work (unless at the beginning or end of the reporting period), or failing to report the day of the week were included in the main analysis but excluded from a subsequent sensitivity analysis (S4, see below). No imputations were made if travel data appeared incomplete. We derived three specific mode share outcomes. These were changes in the share of trips (i) involving any active travel, (ii) involving any public transport, and (iii) made entirely by car, reflecting the aims and nature of the intervention.

Change in objective commute distance was determined using self-reported home and workplace postcodes and calculated using a geographic information system (GIS) (Additional file 1).

\section{Exposure}

We derived an objective, ego-centred [25] measure of exposure to the intervention for each individual, based on the proximity of their baseline home postcode to the nearest busway stop or path access point. We recognised that use of the busway was unlikely to be limited to a specific distance buffer, which meant that assigning individuals to simple 'intervention' and 'control' groups based 


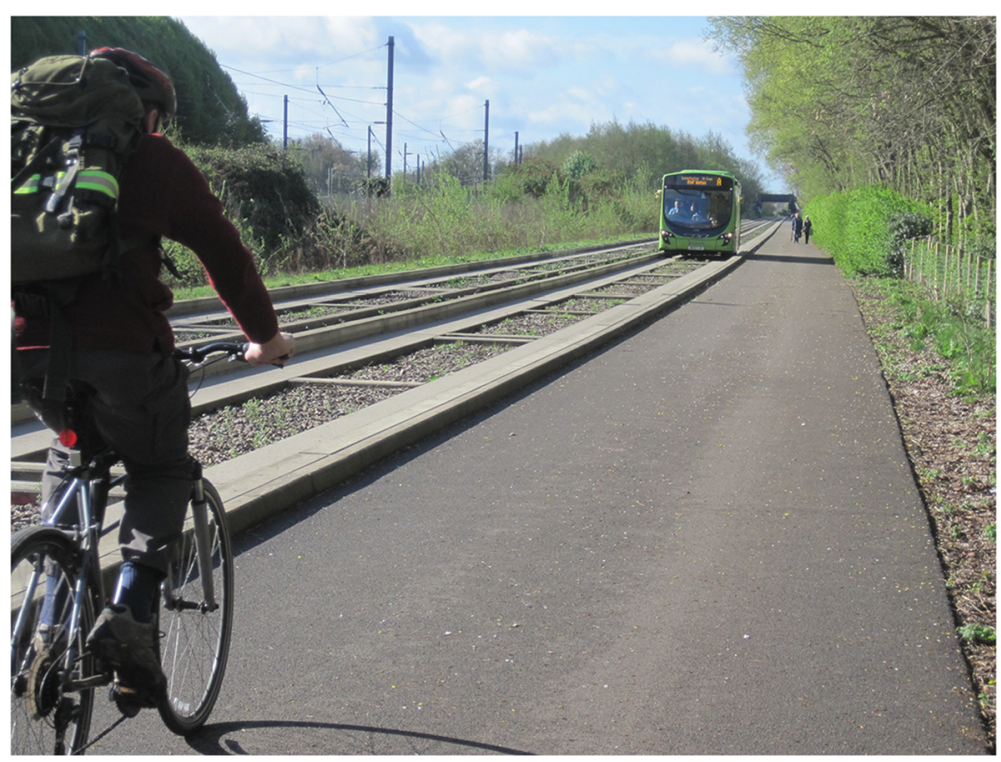

Fig. 1 The Cambridgeshire Guided Busway

on area of residence would not be meaningful [18]. Preliminary descriptive analyses also showed statistically significant differences in some covariates between different parts of the study area, which reinforced the decision to treat exposure to the intervention as a continuous variable. We expected a given increment in distance to have a smaller effect on travel behaviour as distance increased, and therefore defined exposure using a square root transformation of the negative of the distance (hence shorter distance $=$ greater proximity = greater exposure). This produced comparable, but slightly more conservative and more easily interpretable, model outputs to those produced by a log transformation, the most obvious alternative.

\section{Covariates}

We controlled for alternative explanations such as life events which have been shown to be associated with travel behaviour change. Changes in home or work location could affect travel behaviour [26-28] and were operationalized for analysis as change in objective commute distance, ${ }^{1}$ change in estimated travel time to work by public transport, and change in distance from home to the busway. Further details are provided in Additional file 1. We also controlled for two additional changes: a change in workplace parking provision [29] and a change in the number of children in the household [26].

The following additional covariates were included: gender, age, commute distance, the availability of (free) parking at work, education level, car ownership, access to a bicycle, presence of children in the household, presence of a limiting long-term health condition, difficulty walking, the mental (MCS-8) and physical (PCS-8) summary scores of the SF-8 [30] and residential settlement size (the Urban Rural Classification of the Census Output Area) [31], all assessed at baseline (Table 1). We tested for interaction effects between exposure to the intervention and commute distance, gender, change in estimated travel time to work by public transport, and change in commute distance. We calculated the interaction terms by multiplying the mean-adjusted values of two continuous variables with each other, or in case of a nominal or ordinal variable, the mean-adjusted value if a condition was met (i.e., male $=0$; female $=$ value) .

\section{Analyses}

Changes in mode share were grouped into five categories corresponding to a large (30\% to $100 \%$ ) decrease, a small $(<30 \%)$ decrease, no change, a small $(<30 \%)$ increase and a large (30\% to $100 \%$ ) increase, except for the change in public transport mode share which was grouped into three categories (decrease, no change and increase) due to its distribution. A change of $30 \%$ (i.e., three trips out of ten) or more was considered a substantial change as it corresponds in most cases to a change affecting more than one day per week. Change in the weekly number of trips was similarly grouped into five categories: large decrease ( 3 trips or more), small ( $<3$ trips) decrease, no change, small ( $<3$ trips) increase and large increase (3 trips or more) (Table 2).

Effects on mode share and number of trips were tested with multivariable multinomial logistic regression models, progressively adjusted as follows: (1) unadjusted, (2) adjusted for commute characteristics, (3) adjusted for commute and sociodemographic characteristics, and (4) maximally adjusted for commute, sociodemographic and 
Table 1 Summary of participant characteristics, baseline travel behaviour and exposure to intervention

\begin{tabular}{|c|c|c|c|c|c|c|c|c|c|c|c|c|c|}
\hline & & \multicolumn{4}{|c|}{ All participants at wave 1} & \multicolumn{4}{|c|}{$\begin{array}{l}\text { Analysis sample } \\
\text { (valid wave } 1 \text { and wave 4) }\end{array}$} & \multicolumn{4}{|c|}{$\begin{array}{l}\text { Participants in wave 1, but } \\
\text { not wave } 4 \text { (drop-out) }\end{array}$} \\
\hline & & $n$ & $\%$ & mean & st.d. & $\bar{n}$ & $\%$ & mean & st.d. & $\bar{n}$ & $\%$ & mean & st.d. \\
\hline \multicolumn{2}{|c|}{ Distance from home to busway $(\mathrm{km})$} & 1155 & & 6.6 & 7.8 & 466 & & 6.5 & 7.9 & 659 & & 6.7 & 7.7 \\
\hline \multicolumn{2}{|l|}{ Proximity to busway $(-\sqrt{ } \mathrm{km})$} & 1155 & & -2.2 & 1.4 & 466 & & -2.1 & 1.4 & 659 & & -2.2 & 1.4 \\
\hline \multicolumn{2}{|l|}{ Commute distance (km) } & 1158 & & 11.1 & 9.4 & 469 & & 10.9 & 9.4 & 659 & & 11.4 & 9.5 \\
\hline \multicolumn{2}{|c|}{ Change in commute distance $(\mathrm{km})$} & & & & & 450 & & 0.2 & 4.9 & & & & \\
\hline \multicolumn{2}{|c|}{$\begin{array}{l}\text { Change in travel time to work by } \\
\text { public transport (min) }\end{array}$} & & & & & 443 & & -0.1 & 11.1 & & & & \\
\hline \multicolumn{2}{|c|}{ Change in proximity to busway (km) } & & & & & 450 & & 0.2 & 4.9 & & & & \\
\hline \multirow[t]{2}{*}{ Moved home } & No & & & & & 359 & 76.4 & & & & & & \\
\hline & Yes & & & & & 111 & 23.6 & & & & & & \\
\hline \multirow[t]{2}{*}{ Moved workplace } & No & & & & & 357 & 76 & & & & & & \\
\hline & Yes & & & & & 113 & 24 & & & & & & \\
\hline \multirow[t]{2}{*}{ Gender } & Male & 367 & 31.5 & & & 157 & 33.4 & & & 205 & 30.9 & & \\
\hline & Female & 797 & 68.5 & & & 313 & 66.6 & & & 459 & 69.1 & & \\
\hline \multirow[t]{5}{*}{ Age } & $\leq 30$ & 197 & 17 & & & 58 & 12.4 & & & 135 & 20.4 & & \\
\hline & $31-40$ & 327 & 28.2 & & & 111 & 23.7 & & & 207 & 31.3 & & \\
\hline & $41-50$ & 305 & 26.3 & & & 139 & 29.6 & & & 160 & 24.2 & & \\
\hline & $51-60$ & 246 & 21.2 & & & 122 & 26 & & & 114 & 17.2 & & \\
\hline & $61+$ & 85 & 7.3 & & & 39 & 8.3 & & & 46 & 6.95 & & \\
\hline \multirow[t]{2}{*}{ Education level } & Degree & 837 & 72.3 & & & 350 & 74.6 & & & 471 & 71.4 & & \\
\hline & Less than degree & 321 & 27.7 & & & 119 & 25.4 & & & 189 & 28.6 & & \\
\hline \multirow[t]{2}{*}{ Housing tenure } & Not owner & 319 & 27.5 & & & 103 & 22 & & & 204 & 30.9 & & \\
\hline & Owner & 840 & 72.5 & & & 365 & 78 & & & 457 & 69.1 & & \\
\hline \multirow[t]{2}{*}{ Driving licence } & No & 113 & 9.7 & & & 37 & 7.9 & & & 72 & 10.9 & & \\
\hline & Yes & 1049 & 90.3 & & & 432 & 92.1 & & & 591 & 89.1 & & \\
\hline \multirow[t]{2}{*}{ Access to a bicycle } & No & 182 & 15.7 & & & 63 & 13.5 & & & 191 & 28.8 & & \\
\hline & Yes & 974 & 84.3 & & & 404 & 86.51 & & & 473 & 71.2 & & \\
\hline \multirow[t]{2}{*}{ Children in household } & No & 820 & 70.5 & & & 324 & 68.9 & & & 473 & 71.2 & & \\
\hline & Yes & 344 & 29.6 & & & 146 & 31.1 & & & 191 & 28.8 & & \\
\hline \multirow[t]{2}{*}{ New child in household } & No & & & & & 444 & 94.5 & & & & & & \\
\hline & Yes & & & & & 26 & 5.5 & & & & & & \\
\hline \multicolumn{2}{|l|}{ Physical health (PCS-8) } & 1156 & & 53.7 & 6.3 & 468 & & 53.9 & 6.3 & 658 & & 53.6 & 6.4 \\
\hline \multicolumn{2}{|l|}{ Mental health (MCS-8) } & 1156 & & 50.6 & 8.1 & 468 & & 51.7 & 7.1 & 658 & & 49.9 & 8.6 \\
\hline Limiting health condition & No & 1040 & 89.7 & & & 429 & 91.7 & & & 582 & 88.1 & & \\
\hline & Yes & 119 & 10.3 & & & 39 & 8.3 & & & 79 & 12 & & \\
\hline Difficulty walking & No & 1143 & 98.5 & & & 464 & 98.9 & & & 651 & 98.3 & & \\
\hline & Yes & 18 & 1.6 & & & 5 & 1.1 & & & 11 & 1.7 & & \\
\hline Type of settlement & Urban $(>10,000)$ & 767 & 66 & & & 316 & 67.4 & & & 427 & 64.3 & & \\
\hline & Town \& Fringe & 226 & 19.4 & & & 80 & 17.1 & & & 144 & 21.7 & & \\
\hline & $\begin{array}{l}\text { Village, Hamlet \& Isolated } \\
\text { Dwellings }\end{array}$ & 170 & 14.6 & & & 73 & 15.6 & & & 93 & 14.0 & & \\
\hline Car parking at work & No & 371 & 32.3 & & & 151 & 32.4 & & & 208 & 31.8 & & \\
\hline & Yes, paid & 351 & 30.6 & & & 143 & 30.7 & & & 201 & 30.7 & & \\
\hline & Yes, free & 427 & 37.2 & & & 172 & 36.9 & & & 245 & 37.5 & & \\
\hline
\end{tabular}


Table 1 Summary of participant characteristics, baseline travel behaviour and exposure to intervention (Continued)

\begin{tabular}{|c|c|c|c|c|c|c|c|c|c|c|c|c|c|}
\hline & & \multicolumn{4}{|c|}{ All participants at wave 1} & \multicolumn{4}{|c|}{$\begin{array}{l}\text { Analysis sample } \\
\text { (valid wave } 1 \text { and wave 4) } \\
\end{array}$} & \multicolumn{4}{|c|}{$\begin{array}{l}\text { Participants in wave 1, but } \\
\text { not wave } 4 \text { (drop-out) }^{\text {a }}\end{array}$} \\
\hline & & $n$ & $\%$ & mean & st.d. & $n$ & $\%$ & mean & st.d. & $n$ & $\%$ & mean & st.d. \\
\hline \multirow{2}{*}{$\begin{array}{l}\text { Change in car parking at work from } \\
\text { parking to no parking }\end{array}$} & No & & & & & 405 & 86.2 & & & & & & \\
\hline & Yes & & & & & 65 & 13.8 & & & & & & \\
\hline \multirow[t]{3}{*}{ Car ownership } & No car & 175 & 15.0 & & & 57 & 12.1 & & & 112 & 16.9 & & \\
\hline & One car & 525 & 45.1 & & & 225 & 47.9 & & & 287 & 43.2 & & \\
\hline & Two or more cars & 464 & 39.9 & & & 188 & 40.0 & & & 265 & 39.9 & & \\
\hline $\begin{array}{l}\text { Baseline proportion of trips involving } \\
\text { any active travel }\end{array}$ & & 1141 & & 0.67 & 0.43 & 467 & & 0.69 & 0.42 & 648 & & 0.65 & 0.44 \\
\hline $\begin{array}{l}\text { Baseline proportion of trips involving } \\
\text { any public transport }{ }^{b}\end{array}$ & & 1141 & & 0.15 & 0.32 & 467 & & 0.15 & 0.32 & 648 & & 0.14 & 0.32 \\
\hline $\begin{array}{l}\text { Baseline proportion of trips made } \\
\text { entirely by } \text { car }^{\text {b }}\end{array}$ & & 1141 & & 0.27 & 0.4 & 467 & & 0.24 & 0.38 & 648 & & 0.29 & 0.42 \\
\hline Baseline number of commute trips ${ }^{c}$ & & 1164 & & 9.2 & 2.8 & 470 & & 9.3 & 2.6 & 664 & & 9.2 & 2.8 \\
\hline
\end{tabular}

spatial characteristics. Age and gender were always included, and other explanatory variables associated with the outcome at $p<0.25$ in unadjusted models were included in the adjusted models [32]. Interaction effects were included only if significant at $p<0.05$. None of the interaction effects met that condition.
Four sensitivity tests were conducted on each maximally adjusted model: (S1) including the baseline value of the outcome (mode share or number of trips as appropriate) as a continuous independent variable; (S2) including workplace parking and car ownership; (S3) restricted to individuals who did not move home or workplace between baseline

Table 2 Distributions of main outcome variables

\begin{tabular}{|c|c|c|c|c|c|}
\hline & & Number & Percent & Mean & st.d. \\
\hline \multirow[t]{5}{*}{ Change in proportion of trips involving any active travel } & Decrease of $30 \%$ or more & 58 & 12.9 & & \\
\hline & Decrease of $<30 \%$ & 36 & 8.0 & & \\
\hline & No change & 276 & 61.2 & & \\
\hline & Increase of $<30 \%$ & 34 & 7.5 & & \\
\hline & Increase of $30 \%$ or more & 47 & 10.4 & & \\
\hline \multirow[t]{3}{*}{ Change in proportion of trips involving any public transport } & Decrease & 55 & 12.2 & & \\
\hline & No change & 341 & 75.6 & & \\
\hline & Increase & 55 & 12.2 & & \\
\hline \multirow[t]{5}{*}{ Change in proportion of trips made entirely by car } & Decrease of $30 \%$ or more & 31 & 6.9 & & \\
\hline & Decrease of $<30 \%$ & 39 & 8.7 & & \\
\hline & No change & 286 & 63.4 & & \\
\hline & Increase of $<30 \%$ & 42 & 9.3 & & \\
\hline & Increase of $30 \%$ or more & 53 & 11.8 & & \\
\hline \multirow[t]{5}{*}{ Change in number of trips } & Decrease of 3 trips or more & 87 & 18.6 & & \\
\hline & Decrease of $<3$ trips & 77 & 16.4 & & \\
\hline & No change & 194 & 41.4 & & \\
\hline & Increase of $<3$ trips & 62 & 13.2 & & \\
\hline & Increase of 3 trips or more & 49 & 10.5 & & \\
\hline Change in commute distance $(\mathrm{km})$ & & 450 & & 0.20 & 4.9 \\
\hline
\end{tabular}


and follow-up; and (S4) restricted to individuals who had 'perfectly' completed travel diaries at both time points (see above). Additional sensitivity tests restricting the analyses to individuals who reported more than four or more than six trips showed no impact on the effect estimates (data not shown).

\section{Results}

Of the 470 participants included in analysis, 175 reported a change in their active travel mode share for commuting (average change of $-1.3 \%$ ), 110 a change in their public transport mode share (average change $-1.0 \%$ ) and 165 a change in their car mode share (average change $+3.4 \%$ ).

\section{Changes in commute mode share Trips involving any active travel}

Proximity to the busway was significantly associated with a small decrease in active travel mode share in unadjusted analyses, but in the maximally adjusted models proximity predicted a large increase in active travel mode share (relative risk ratio [RRR] 1.80, $95 \%$ confidence interval [95\% CI] 1.27 to 2.55 ) and reduced the likelihood of a small decrease in active travel mode share (RRR 0.47, 95 \% CI 0.28 to 0.81 ) (Table 3 and Additional file 2). In other words, commuters living $4 \mathrm{~km}$ from the busway were almost twice as likely to report a substantial increase in their active travel mode share, and half as likely to report a small decrease, than those living $9 \mathrm{~km}$ away. Both associations were strengthened in analyses restricted to participants who did not move home or workplace.

In addition, home ownership reduced the likelihood of a small decrease in active travel mode share, whereas those aged 51-60 were more likely to report a large decrease than those aged 31-40. Commuters with a child in their household were more likely to report a small increase in active travel mode share, whereas a large increase was more likely among those whose commute distance had increased or who lived in very small settlements and less likely among those with degree-level education.

\section{Trips involving any public transport}

As expected, in the unadjusted model commuters living closer to the busway were less likely to reduce their public transport mode share, but this effect became insignificant after adjustment for commute characteristics and remained insignificant after further adjustment (Table 4 and Additional file 3).

Several covariates were significantly associated with a change in public transport mode share. Having a bicycle or higher self-rated physical health (PCS-8) reduced the likelihood of a decrease in public transport mode share, whereas living in villages or smaller settlements rather than urban areas predicted an increase in public transport mode share.

\section{Trips made entirely by car}

Proximity to the busway did not predict changes in car mode share in unadjusted analyses, but after adjustment for commute characteristics and all further adjustments it was associated with a large decrease in car mode share (RRR 2.09, 95 \% CI 1.35 to 3.21) (Table 5 and Additional file 4). This effect was robust to the sensitivity analyses, and corresponds to a doubling of the likelihood of a large decrease in car use between those living $9 \mathrm{~km}$ from the busway and those living $4 \mathrm{~km}$ away.

Furthermore, an increase in commute distance was associated with a small decrease in car mode share, while those with children or living in less urban settlements were more likely to report a large decrease in car mode share. Commuters aged 51-60 were more likely to report a large increase in car mode share, whereas those with higher selfrated mental health (MCS-8) were less likely to do so.

\section{Change in number of commute trips}

Proximity to the intervention did not predict a change in number of trips (Additional file 5). Women were more than twice as likely as men to report a large decrease in trips, those aged 41-50 were less likely than

Table 3 Associations between exposure to busway and changes in active travel mode share

\begin{tabular}{|c|c|c|c|c|}
\hline \multirow[t]{2}{*}{ Outcome } & \multicolumn{4}{|c|}{ Change in active travel mode share } \\
\hline & Large decrease & Small decrease & Small increase & Large increase \\
\hline Unadjusted & $0.94(0.77,1.14)$ & $0.77(0.62,0.97)^{*}$ & $0.99(0.77,1.27)$ & $1.15(0.90,1.46)$ \\
\hline Adjusted for commute characteristics & $1.09(0.80,1.47)$ & $0.57(0.35,0.92)^{*}$ & $0.63(0.37,1.06)$ & $1.53(1.14,2.06)^{* *}$ \\
\hline Adjusted for commute and sociodemographic characteristics & $1.04(0.75,1.44)$ & $0.47(0.28,0.81)^{* *}$ & $0.64(0.35,1.15)$ & $1.57(1.14,2.15)^{* *}$ \\
\hline Maximally adjusted model & $1.08(0.77,1.50)$ & $0.47(0.28,0.81)^{* *}$ & $0.69(0.38,1.26)$ & $1.80(1.27,2.55)^{* *}$ \\
\hline \multicolumn{5}{|l|}{ Sensitivity tests: } \\
\hline S1. Including baseline & $1.07(0.74,1.54)$ & $0.48(0.28,0.81)^{* *}$ & $0.70(0.38,1.27)$ & $1.71(1.15,2.55)^{* *}$ \\
\hline S2. Including parking & $1.19(0.85,1.68)$ & $0.47(0.27,0.81)^{* *}$ & $0.68(0.36,1.28)$ & $1.94(1.34,2.80)^{* *}$ \\
\hline S3. Non-movers only & $1.06(0.68,1.65)$ & $0.31(0.10,0.94)^{*}$ & $0.79(0.36,1.70)$ & $1.84(1.16,2.90)^{* *}$ \\
\hline S4. Perfect diaries only & $1.26(0.85,1.88)$ & $0.35(0.17,0.73)^{*}$ & $0.58(0.27,1.25)$ & $1.80(1.20,2.70)^{* *}$ \\
\hline
\end{tabular}

Multinomial logistic regression with 'no change' as the reference outcome category

Exposure to the busway was defined as the negative square root of the distance from home to busway

Values tabulated are relative risk ratios (95\% confidence intervals)

${ }^{*} p<0.05 ;{ }^{* *} p<0.01$ 
Table 4 Associations between exposure to busway and changes in public transport mode share

\begin{tabular}{lll}
\hline Outcome & \multicolumn{2}{l}{$\begin{array}{l}\text { Change in public transport } \\
\text { mode share }\end{array}$} \\
\cline { 2 - 3 } & Decrease & Increase \\
\hline Unadjusted & $\mathbf{0 . 8 2}(\mathbf{0 . 6 8}, \mathbf{0 . 9 9})^{*}$ & $0.94(0.77,1.14)$ \\
$\begin{array}{l}\text { Adjusted for commute } \\
\text { characteristics }\end{array}$ & $0.90(0.67,1.20)$ & $1.07(0.82,1.41)$ \\
$\begin{array}{l}\text { Adjusted for commute } \\
\text { and sociodemographic } \\
\text { characteristics }\end{array}$ & $0.92(0.68,1.25)$ & $1.16(0.86,1.55)$ \\
$\begin{array}{l}\text { Maximally adjusted } \\
\text { model }\end{array}$ & $0.91(0.66,1.24)$ & $1.26(0.92,1.72)$ \\
Sensitivity tests: & & \\
S1. Including baseline & $0.93(0.63,1.37)$ & \\
S2. Including parking & $0.92(0.66,1.27)$ & $1.28(0.93,1.76)$ \\
S3. Non-movers only & $0.99(0.66,1.49)$ & $1.30(0.91,1.86)$ \\
S4. Perfect diaries only & $1.03(0.71,1.48)$ & $1.43(1.00,2.05)$ \\
\hline
\end{tabular}

Multinomial logistic regression with 'no change' as the reference outcome category

Exposure to the busway was defined as the negative square root of the distance from home to busway

Values tabulated are relative risk ratios (95\% confidence intervals)

${ }^{*} p<0.05 ;{ }^{* *} p<0.01$

those aged 31-40 to report a small increase, and those with a degree were more likely to report a large increase.

\section{Change in commute distance}

While the intervention reduced the distance from home to work on foot for 55 individuals (mean change $-42 \mathrm{~m}$, s.d. $173 \mathrm{~m}$ ), the majority of individuals experiencing a change in distance had moved home or workplace. Proximity to the busway did not predict a reduction in commute distance that was not due to moving $(p>0.25$, data not shown).

\section{Discussion}

\section{Principal findings}

Our findings provide new evidence linking new transport infrastructure with travel behaviour change. After adjusting for multiple potential confounders, exposure to the intervention (proximity to the busway) was significantly associated with the likelihood of making large changes in commute mode choice. Individuals who lived closer to the busway were more likely to report a large increase in the proportion of their commute trips that involved active travel than those who lived further away. Exposure to the intervention also predicted a large decrease in the share of commute trips made entirely by car and 'prevented' against a small decrease in the share of commute trips involving active travel.

\section{Interpretation}

The busway was intended to increase public transport use, mainly by attracting car users [33]. We found no significant effect on overall public transport mode share in adjusted models, although the differences observed were in the expected direction. This may reflect the relatively low proportion of public transport trips in our sample at baseline, and the fact that shifts from conventional bus to guided bus services would not have been captured by this measure. The high local prevalence of cycling may explain why this particular intervention showed a clearer effect on active travel in our sample, and the shift in commute mode share from the car towards active travel may also have contributed to a desirable reduction in traffic congestion. Furthermore, since the intervention was not associated with changes in commute distance or trip frequency, it is plausible that this modal shift may be translated into an increase in time spent in active travel and consequent health benefits.

Table 5 Associations between exposure to busway and changes in car mode share

\begin{tabular}{|c|c|c|c|c|}
\hline \multirow[t]{2}{*}{ Outcome } & \multicolumn{4}{|c|}{ Change in car mode share } \\
\hline & Large decrease & Small decrease & Small increase & Large increase \\
\hline Unadjusted & $1.16(0.86,1.57)$ & $0.85(0.68,1.07)$ & $0.82(0.66,1.01)$ & $0.86(0.70,1.05)$ \\
\hline Adjusted for commute characteristics & $1.71(1.20,2.44)^{* *}$ & $0.60(0.37,0.97)^{*}$ & $0.70(0.45,1.07)$ & $1.13(0.85,1.51)$ \\
\hline Adjusted for commute and sociodemographic characteristics & $1.71(1.17,2.49)^{* *}$ & $0.59(0.36,0.99)^{*}$ & $0.65(0.41,1.03)$ & $1.08(0.79,1.48)$ \\
\hline Maximally adjusted model & $2.09(1.35,3.21)^{* *}$ & $0.64(0.38,1.08)$ & $0.71(0.44,1.14)$ & $1.10(0.80,1.52)$ \\
\hline \multicolumn{5}{|l|}{ Sensitivity tests: } \\
\hline S1. Including baseline & $2.57(1.47,4.49)^{* *}$ & $0.65(0.38,1.11)$ & $0.71(0.44,1.13)$ & $1.03(0.73,1.44)$ \\
\hline S2. Including parking & $2.39(1.47,3.91)^{* *}$ & $0.61(0.33,1.14)$ & $0.72(0.45,1.15)$ & $1.17(0.84,1.64)$ \\
\hline S3. Non-movers only & $1.84(1.06,3.21)^{*}$ & $0.71(0.37,1.38)$ & $0.59(0.29,1.20)$ & $1.10(0.72,1.68)$ \\
\hline S4. Perfect diaries only & $2.17(1.30,3.62)^{* *}$ & $0.52(0.26,1.03)$ & $0.75(0.40,1.40)$ & $1.13(0.76,1.68)$ \\
\hline
\end{tabular}

Multinomial logistic regression with 'no change' as the reference outcome category

Exposure to the busway was defined as the negative square root of the distance from home to busway Values tabulated are relative risk ratios (95\% confidence intervals)

${ }^{*} p<0.05 ;{ }^{* *} p<0.01$ 
For certain outcomes the intervention effect became significant only after adjustment for covariates, which indicates that the effect was suppressed by the commute and socioeconomic characteristics of the participants. This probably reflects the fact that exposure to the intervention was not evenly distributed in relation to those characteristics, and the statistical relationship between exposure and behaviour change was therefore masked by the correlation between exposure and the covariates.

Travel behaviour change was more strongly associated with the intervention than with moving or becoming a parent. Controlling for other changes unrelated to the intervention eliminated several plausible alternative explanations for the changes in travel behaviour. Moreover, the sensitivity analyses restricted to participants who had not moved or experienced a change in workplace parking provision confirmed or even strengthened the associations observed in the main analyses, indicating that behaviour change can occur independently of major life events.

For some covariates, the associations differed from those typically observed in cross-sectional studies. For example we found that an increase in commute distance corresponded with a small decrease in car commuting, while longer commute distances are more often associated with a higher likelihood of car commuting. One explanation for this is that individuals making greater use of a given mode of transport at baseline have a higher chance of reducing its use over time than those who never or rarely used it, and more generally it is important to note that correlates of change in behaviour over time are likely to differ from correlates of behaviour at a single time point.

\section{Strengths and limitations}

The key strengths of this study include the use of an individually computed measure of intervention exposure, multiple measures of behaviour change outcomes and a large number of covariates to eliminate alternative causal explanations. Nevertheless, the study has a number of limitations. The first is that it was not possible to compare outcomes in intervention and control groups that differed only in their level of exposure to the intervention. However, natural experimental studies such as ours are often the only feasible intervention study design in this field. A second limitation is that travel behaviour was self-reported, which could threaten the validity of the outcome measures by intentional or unintentional misreporting. A third is that we applied a measure of exposure based solely on participants' home addresses. Considering the working location and commute route would capture exposure more fully [25], and more detailed measures of individual exposure to environmental change may strengthen the evidence of intervention effects [9, 34]. However, our final choice of exposure measure followed a consideration of several alternatives, and we expected comparatively little variation in exposure by workplace because all respondents worked at locations that were at least notionally accessible using the busway.

\section{Implications}

The intervention had a substantial influence on the proportion of commute trips that involved at least some active travel. This has the potential to improve health, whether directly or via higher levels of overall physical activity. Further longitudinal analysis will be necessary to determine whether these changes in mode share have resulted in increased physical activity and overall health gain.

The study investigated the effect of new infrastructure on travel behaviour only one year after it became fully operational. Travel mode choice is known to be habitual and strongly predicted by previous behaviour, which suggests that people may require more time to change their behaviour [35]. The longer-term effects of the intervention may therefore be larger or smaller than those observed in this analysis [8].

While the scale of this particular intervention made it a good subject for public health evaluation, opportunities to implement exactly the same type of intervention on a similarly large scale may be limited, and the findings of our cohort study may not be directly generalizable to other study populations and settings. However, this is true of much natural experimental research in public health [18]. The principles of the intervention and study design could nevertheless be generalized, and similar studies in different settings are necessary to build a body of evidence that is not specific to a single context. Such studies could corroborate or disconfirm our findings, and will contribute to the development of more conclusive evidence of a causal relationship between changes in the built environment and change in population activity patterns and health.

\section{Conclusion}

Our findings show that the introduction of new transport infrastructure was associated with travel behaviour change. Over time, commuters with a higher level of exposure to the guided busway were more likely to have increased the proportion of their commute trips involving active travel, and to have reduced the proportion made entirely by car, than those with a lower level of exposure. The intervention was not associated with a change in the number or distance of commute trips, which suggests that the modal shift in commuting patterns may be translated into an increase in time spent in physical activity on the journey to and from work. 
These findings add to a growing body of evidence to support the assumption that changing the built environment can bring about changes in travel behaviour and contribute to consequent population health gain.

\section{Endnotes}

${ }^{1}$ Except for the analysis in which change in commute distance was the outcome.

\section{Additional files}

\section{Additional file 1: Calculation of intervention exposure and commute distance and bus travel time [36-41].}

Additional file 2: Predictors of change in active travel mode share. Additional file 3: Predictors of a change in public transport mode share.

Additional file 4: Predictors of change in car mode share.

Additional file 5: Predictors of change in number of commute trips.

\section{Competing interests}

The authors declare that they have no competing interests.

\section{Authors' contributions}

DO led the design of the overall study in collaboration with RM (and others, see Acknowledgements). EH and DO conceived of the analysis for this paper and wrote the manuscript. EH conducted the analysis in collaboration with JP and drafted the manuscript. JP and RM advised on the design of the study and the interpretation of the emerging findings and contributed to the critical revision of the paper. All authors read and approved the final manuscript. Other contributions are detailed in the Acknowledgements section.

\section{Acknowledgements}

The Commuting and Health in Cambridge study was developed by David Ogilvie, Simon Griffin, Andy Jones and Roger Mackett and initially funded under the auspices of the Centre for Diet and Activity Research (CEDAR), a UKCRC Public Health Research Centre of Excellence. Funding from the British Heart Foundation, Economic and Social Research Council, Medical Research Council, National Institute for Health Research and the Wellcome Trust, under the auspices of the UK Clinical Research Collaboration, is gratefully acknowledged. The study is now funded by the National Institute for Health Research Public Health Research programme (project number 09/3001/06: see http://www.nets.nihr.ac.uk/projects/phr/09300106). David Ogilvie is supported by the Medical Research Council [Unit Programme number MC_UP_12015/6] and Jenna Panter is supported by an NIHR post-doctoral fellowship. The views and opinions expressed herein are those of the authors and do not necessarily reflect those of the NIHR PHR programme or the Department of Health. The funders had no role in study design, data collection and analysis, the decision to publish, or the preparation of the manuscript. We thank all staff from the MRC Epidemiology Unit Functional Group Team, in particular for study coordination and data collection (led by Cheryl Chapman and Fiona Whittle) and data management. We also thank Alice Dalton for computing the proximity measures used in this analysis and Louise Foley for her contribution to preparing the questionnaire data for analysis.

\section{Author details}

'MRC Epidemiology Unit and UKCRC Centre for Diet and Activity Research (CEDAR), School of Clinical Medicine, University of Cambridge, Cambridge Biomedical Campus, Box 285, Cambridge CB2 0QQ, UK. ' Department of Civil, Environmental and Geomatic Engineering, University College London, Gower Street, London WC1E 6BT, UK.

Received: 15 December 2014 Accepted: 12 June 2015 Published online: 20 June 2015

\section{References}

1. Chief Medical O. Start active, stay active: a report on physical activity from the four home countries'. Chief medical officers. London: Department of Health; 2011.

2. Hamer M, Chida Y. Active commuting and cardiovascular risk: a meta-analytic review. Prev Med. 2008:46:9-13.

3. Saelens BE, Handy SL. Built environment correlates of walking: a review. Med Sci Sports Exerc. 2008;40 Suppl 7:S550-66.

4. Handy SL, Boarnet MG, Ewing R, Killingsworth RE. How the built environment affects physical activity views from urban planning. Am J Prev Med. 2002;23 Suppl 2:64-73.

5. Ewing R, Cervero R. Travel and the built Environment, a meta analyses. J Am Plann Assoc. 2010;76:265-94.

6. Heinen $\mathrm{E}$, van Wee $\mathrm{B}$, Maat $\mathrm{K}$. Commuting by bicycle: an overview of the literature. Transp Rev. 2009;30:59-96.

7. Fraser SDS, Lock K. Cycling for transport and public health: a systematic review of the effect of the environment on cycling. Eur J Public Health. 2011;21:738-43.

8. Goodman A, Sahlqvist S, Ogilvie D. New walking and cycling routes and increased physical activity: One- and 2-year findings from the UK iConnect study. Am J Public Health. 2014;104:e38-46.

9. Hooper P, Giles-Corti B, Knuiman M. Evaluating implementation and active living impacts of a state government planning designed to create walkebale neighborhoods in Perth, Western Australia. Am J Health Promot. 2014;28 Suppl 3:5-18.

10. National Institute for Health and Care Excellence (Nice). Physical activity and the environment evidence update April 2014 evidence update 57. 2014. London: National Institute for Health and Care Excellence; 2014.

11. Ferdinand OA, Sen B, Rahurkar S, Engler S, Menachemi N. The relationship between built environments and physical activity: a systematic review. Am J Public Health. 2012;102:e7-13.

12. McCormack GR, Shiell A. In search of causality: a systematic review of the relationship between the built environment and physical activity among adults. Int J Behav Nutr Phys Act. 2011;8:125

13. Bauman A, Bull F. Environmental correlates of physical activity and walking in adults and children. London: National Institute of Health and Clinical Excellence; 2007.

14. Saunders LE, Green JM, Petticrew MP, Steinbach R, Roberts H. What are the health benefits of active travel? A systematic review of trials and cohort studies. PLoS One. 2013;8:e69912.

15. Ogilvie D, Foster CE, Rothnie H, Cavill N, Hamilton V, Fitzsimons CF, et al. Interventions to promote walking: systematic review. BMJ. 2007;334:1204.

16. Smith RD, Petticrew M. Public health evaluation in the twenty-first century: time to see the wood as well as the trees. J Public Health. 2010;32:2-7.

17. Woodcock J, Edwards P, Tonne C, Armstrong BG, Ashiru O, Banister D, et al. Public health benefits of strategies to reduce greenhouse-gas emissions: urban land transport. Lancet. 2009;374:1930-43.

18. Craig P, Cooper C, Gunnell D, Haw S, Lawson K, Macintyre S, et al. Using natural experiments to evaluate population health interventions: new Medical Research Council guidance. J Epidemiol Community Health. 2012;66:1182-6.

19. Ogilvie D, Griffin S, Jones A, Mackett R, Guell C, Panter J, et al. Commuting and health in Cambridge: a study of a 'natural experiment' in the provision of new transport infrastructure. BMC Public Health. 2010;10:703.

20. Office of National Statistics (ONS), 2011. via: http://www.neighbourhood. statistics.gov.uk. Accessed 02 July 2014.

21. The Busway.(http://www.thebusway.info/). Accessed 2 July 2014.

22. Atkins: Transport Assessment. Cambridgeshire guided busway. Cambridge: Cambridgeshire Country Council; 2004.

23. British Broadcasting Corporation (BBC). Cambridgeshire's Guided Bus. http://www.bbc.co.uk/cambridgeshire/content/articles/2007/03/14/ guidedbus_feature.shtml, accessed 2 July 2014.

24. Panter J, Griffin S, Jones A, Mackett R, Ogilvie D. Correlates of time spent walking and cycling to and from work: baseline results from the commuting and health in Cambridge study. Int J Behav Nutr Phys Act. 2011;8:124.

25. Perchoux C, Chaix B, Cumins S, Kestens Y. Conceptualisation and measurement of environmental exposure in epidemiology: accounting for activity space related to daily mobility. Health Place. 2013;21:86-93.

26. Clark B, Chatterjee K, Melia S, Knies G, Laurie H. Life events and travel behaviour: exploring the inter relationship using UK household longitudinal study. Transportation Res Rec. In press. 
27. Verplanken B, Walker I, Davis A, Jurasek M. Context change and travel mode choice: combining the habit discontinuity and self-activation hypotheses. J Environ Psychol. 2008;28:121-7.

28. Bamberg $\mathrm{S}$. Is a residential relocation a good opportunity to change people's travel behavior? Results from a theory-driven intervention study. Environ Behav. 2006:38:820-40.

29. Scheiner J, Holz-Rau C. A comprehensive study of life course, cohort, and period effect on changes in travel mode use. Transportation Res A-Pol. 2013;47:167-81.

30. Ware J, Kosinski M, Dewey J, Gandek B. How to score and interpret single-item health status measures: a manual for users of the SF- ${ }^{\mathrm{TM}}$ Health survey. Lincoln: Quality Incorporated; 2008.

31. Bibby P, Shephard J. Developing a new classification of urban and rural areas for policy purposes - the methodology. London: Office for National Statistics(ONS); 2004

32. Cambridgeshire County Council. Cambridgeshire guided busway, Statement of case. Cambridge: Cambridgeshire County Council; 2004.

33. Hosmer D, Lemeshow S. Applied logistic regression. Hoboken: Wiley; 2000. p. 96.

34. Christian H, Knuiman M, Bull F, Timperio A, Foster S, Divitini M, et al. A new urban planning code's impact on walking: the residential environment project. Am J Pub Health. 2013;7:1219-28.

35. Scheiner J. Gendered key events in the life course: effects on changes in travel mode choice over time. J Trans Geog. 2014;37:47-60.

36. Ordnance Survey (OS). OS Code Point 2009-2011. Southampton: OS; 2012. Available: http://www.ordnancesurvey.co.uk/business-and-government/ products/code-point.html. Accessed 30 May 2012.

37. Ordnance Survey (OS). OS MasterMap Integrated Transport Network (ITN) Layer. 2013. Southampton: OS. Available: www.ordnancesurvey.co.uk/ oswebsite/products/os-mastermap/itn-layer/index.html. Accessed 25-11-2011.

38. Cambridgeshire County Council. Rights of way, permissive access and registered common land (open access on foot). 2010 [Unpublished]. Available: http://www.cambridgeshire.gov.uk/. Accessed 30 November 2010.

39. Sustrans. About Sustrans. Bristol: Sustrans; 2012. Available: http://www.sustrans. org.uk/about-sustrans. Accessed 3 November 2012.

40. OpenStreetMap. OpenStreetMap: the free wiki world map. 2010. Available: www.openstreetmap.org. Accessed 20 Devember 2010

41. Basemap. Accession: measuring accessibility using GIS. 2013. Available: http://www.basemap.co.uk/software/accession.aspx. Accessed 9 April 2013.

\section{Submit your next manuscript to BioMed Central and take full advantage of:}

- Convenient online submission

- Thorough peer review

- No space constraints or color figure charges

- Immediate publication on acceptance

- Inclusion in PubMed, CAS, Scopus and Google Scholar

- Research which is freely available for redistribution 